\title{
XXXI. On the existence of an undulatory movement accompanying the electric spark
}

\section{Ernest H. Cook D.Sc. F.I.C.}

To cite this article: Ernest H. Cook D.Sc. F.I.C. (1888) XXXI. On the existence of an undulatory movement accompanying the electric spark, Philosophical Magazine Series 5, 26:160, 291-298, DOI: $10.1080 / 14786448808628264$

To link to this article: http://dx.doi.org/10.1080/14786448808628264

曲 Published online: 29 Apr 2009.

Submit your article to this journal $[\pi$

Џ Article views: 2

Q View related articles $\asymp$ 
XXXI. On the Existence of an Undulatory Movement accompanying the Electric Spark. By EnNest H. Соoк, D.Sc. (Lond.), F.I.C., Merchant Venturers' School, Bristol*.

\section{[Plate III.]}

1. TF a powdered substance be scattered over a smooth 1 plate, and the plate held near a pair of terminals between which an electric spark is passing, the powder will arrange itself in a more or less regular series of concentric circles. The common centre of these circles (when the spark is small) appears to be a point directly under that halfway between the terminals. The general appearance presented by these curves will be apparent by a glance at the figures in the Plate which accompanies this paper. These are approximately of the same size as the original. It will be noticed that the figures roughly divide themselves into two classes-(1) those with a clear space in the middle, and (2) those with a circular space, within which the powder is apparently unaffected.

The first class are obtained by holding the plate near to the terminals, the distance varying with the energy of the spark. The cleared space is irregularly elliptical, with its major axis at right angles to the direction of the spark, and the area of the space increases as the intensity of the spark increases. The second class are formed when the distance between the spark and plate is increased until the elliptical space ceases to make its appearance.

2. Mode of Obtaining the Curves.-The most convenient arrangement and the one which gives the best results is as follows:-An induction-coil has each of its terminals connected with a leyden jar, and with one of the handles of a universal discharger. The plate with the powder scattered over it from a sieve is held under the points at a distance which can be varied at pleasure The distance between the terminals, and therefore the length of the spark, can also be easily adjusted. On connecting the coil to the battery a succession of sparks of condensed electricity is obtained, and the powders will be seen to arrange themselves in the manner described. The first spark causes a distinct effect, but a continuance is necessary to bring out the regularity of the curves.

Should it be required to fix the powders in the positions

* Communicated by the Physical Society : read June 23, 1888.

The paper was illustrated by a series of photographs: from two of these the figures in the Plate have been engraved. 
which they have taken up, it is easily done by coating the plate beforehand with a thin layer of gum, and after the experiment breathing on it.

3. Effect of Plate. - When the figures were first obtained it was surmised that they might be caused by the distribution of the electricity over the plate ; that they were in fact modified Lichtenberg's figures. Experiments were therefore made with plates of various substances in different states as regards their surfaces ; for example, whether polished or dull, electrified or unelectrified. The following materials have been examined :- -glass ; resinous cake of electrophorus (a mixture of shell-lac, resin, and Venice turpentine) ; ebonite ; paper (glazed and unglazed); brass (lacquered and unlacquered); zinc ; iron, tinned ditto, galvanized ditto; wood; paraffin; cardboard; and glazed and unglazed earthenware. Except that the rougher surfaces retard and prevent the regularity of the curves, no difference whatever could be observed as due to the substance or condition of the surface.

A piece of plate-glass or polished sheet of metal answers admirably for these experiments. The fact that the production of the curves is independent of the electrical state of the support (and therefore of the powder) justifies the statement that they are not caused by any peculiarity of electrical distribution.

4. Effect of Battery Power, Coil, and Condensation.Experiments were made with the view of finding if variations in the number of cells, in the coil, and in the capacity of the condensers used, caused any alteration in the shape or frequency of the lines in which the powders arranged themselves. Other conditions remaining constant, the battery power employed to drive the coil was changed from ten pint bichromates to one. In no case could any difference be observed in the resulting figures produced. Afterwards the current was still further reduced until it was just sufficient to drive the coil, but so long as this was accomplished the figures remained unaffected.

Several coils were used in the course of the earlier experiments, but finally the work was confined to two. One of these was a very fine instrument by Ruhmkorff, kindly lent to me for the purpose of these experiments by Mr. Francis J. Fry, late High Sheriff of Bristol. It contains a secondary coil, formed of twenty-four miles of wire, is fitted with both spring and mercury interrupters, and with one bichromate (carbons $7^{\prime \prime} \times 3 \frac{1}{2}^{\prime \prime}$ ), gives a regular succession of sparks six inches long. The second was a smaller instrument, by Paterson of London, fitted with a condenser of 100 sheets of $12^{\prime \prime}$ by $5^{\prime \prime}$, 
and capable of giving a small spark of about $1 \frac{1}{2}$ inch long. When coupled with the Leyden jars, of course, the length of spark was much diminished. In no case with either coil was a longer spark employed than 75 inch. No change in the appearance, regularity, or shape of the figures was caused by replacing one coil by another.

The effect of a difference in condensing-power was tried by interposing more jars. Except that the vigour of the spark caused a larger area of cleared space, no alteration could be observed. This is, of course, confirmed by the fact of the different coils, possessing condensers of different areas, giving identical results.

5. Influence of Contact-Breaker.-It might be supposed, as was done by Grove in reference to the stratifications in partial vacuo, that the intermittent character of the currents flowing in the secondary wire caused by the interruptions in the primary-coil by the contact-breaker would have some influence in producing or regulating the curves. This, however, is not the case. The shapes did not alter no matter what coil was employed, and when the mercury-break on the large coil was used in place of the spring, no alteration in the resulting curves was produced. Moreover the curves can be obtained without the use of a coil with its necessary contact-breaker at all. For this purpose it is only necessary to connect each electrode of a Wimshurst machine to one or two Leyden jars, and to allow the highly condensed spark thus obtained to act upon the powder. In fact I have been able to produce the curves in this way without employing any jars at all. With the machine, however, they are far inferior in regularity to those produced by the use of the coil. With a 17-inch plate the best results have been obtained with jars having a total area of foil of about 1500 square inches, a spark of about $3^{\prime \prime}$ long, and the powder $6^{\prime \prime}$ below spark.

6. Nature of Electrodes.-Varying the material forming the points between which the sparks were taken made no difference in the resulting shapes. Thus the same effects are produced by using brass, iron, or carbon points.

7. Influence of the Povdered Substance. - Soon after the first results were obtained and upon trying different substances, it became evident that, although accidental irregularities occurred, yet, upon the whole, the curves were remarkably regular. It was also very soon noticed that the frequency with which they followed each other altered with an alteration of the substance of which they were composed. This induced a desire to compare by measurement the distances between each successive curve. A large number of 
different powders were examined, and the number of lines in a certain distance counted. Several determinations were made and the mean number taken. Although every care was taken to make these measurements as accurately as possible and to avoid sources of error, yet, from the difficulties peculiar to the case, I do not wish to pledge the absolute accuracy of the numbers, but put them forward as approximate only. It first became necessary to ascertain if the fineness of the powder affected the number of lines in a certain length. This was found not to be the case. Provided the degree of fineness was such as to admit of the production of the lines with such an amount of definiteness as sufficed for their measurement, the number of lines was found to be unaltered. The following tabular statement gives the results obtained. The actual experiment was to count the number in a quarter of an inch. These have been multiplied by 4 , hence the regularity of the diminution of the numbers given in the first column :-

No. of lines

in 1 inch.
Substances examined.

88. Silica (powdered sand).
80. Magnesia alba.
68.
Chromic oxide.
64. $\quad$ Antimony sulphide; baric peroxide; fluor spar ; cupric
oxide; red lead; lead acetate; lead oxide; anti-
mony; sulphur; potassium hydrogen tartrate.

60. Borax; cobaltic oxide; starch ; zinc carbonate.

(Binoxide of manganese; baric carbonate; tricalcic

56. $\{$ phosphate; ferrous sulphide; lead chromate; mercuric oxide; binoxide of tin; nickel monoxide; lead carbonate; calcic oxide.

52. Sodium hydrogen carbonate; potassic sulphate ; potassic carbonate; mercurous chloride; carbon; calcic hydrate.

Tannin; salicylic acid; rochelle salt; ammonic sul-

48.

44. phate; baric nitrate; copper sulphate; oxalic acid; sodic chloride; succinic acid; Epsom salts.

The figures (Iron filings; baric chloride; baric sulphate; benzoic were soindefinite as not to permit countacid; strontium chloride; bismuth nitrate; cadmium nitrate; microcosmic salt; potassium chloride; potassium bromide; ammonium chloride; ferrous sulphate; ammonium nitrate; pyrogallol.

8. Effect of Mixture.-While engaged in repeating the experiments, in order to confirm the numbers, it was found that a particular sample of calcic oxide gave 48 lines to the inch instead of 56 , as given in the table. Upon examining 
the sample it was found, however, to be an old one, and to be partially converted into carbonate. It was thus a mixture of oxide and carbonate. This led to the investigation of other mixtures. It was thus proved that the number given by a mixture of two substances was intermediate between those of its constituents. The following were examined, no particular care being taken to mix in definite proportions, but the substances simply ground up together in a mortar:-

\begin{tabular}{|c|c|c|c|c|}
\hline \multirow[t]{2}{*}{ Mixture. } & $\begin{array}{l}\text { Nos. due to each } \\
\text { constituent. }\end{array}$ & \multicolumn{3}{|c|}{ No. obtained. } \\
\hline & \multirow{7}{*}{$\left.\begin{array}{l}56 \\
40 \\
80 \\
40 \\
60 \\
68 \\
60 \\
80\end{array}\right\}$} & Exp. 1. & 2. & 3. \\
\hline 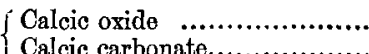 & & 48 & 50 & 48 \\
\hline 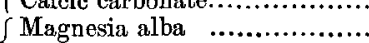 & & 60 & 64 & 56 \\
\hline Oalcic carbonate & & & & \\
\hline Cobaltie oxide........................... & & 64 & 64 & 60 \\
\hline $\begin{array}{l}\text { Chromic oxide } \quad . . . . . . . . . . . . . . . \\
\text { Cobaltic oxide. }\end{array}$ & & 80 & & \\
\hline 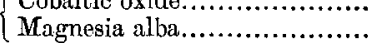 & & 68 & 67 & 68 \\
\hline
\end{tabular}

9. Effect on Liquids.-In order to test if the effect could be produced on the surfaces of liquids the following experiments were made:-In place of a glass plate with the powder scattered over it, there was held under the spark a shallow vessel (an ordinary porcelain evaporating dish answers very well) containing the liquid. So long as the surface was looked directly down upon, no effect could be observed; but when regarded obliquely, minute ripples were seen to be produced upon the surface. No attempt was made to measure these, but they were judged to be of about the same size as those of the powders, that is, between the limits of 88 and 40 to the inch. The following were the liquids tested in this way:-water, mercury, alcohol, ether, glycerin, and henzol.

10. Experiments with Wimshurst Machine.-It has already been stated that the curves obtained by the aid of the machine are much inferior in regularity to those given by the inductioncoil ; in fact, without care they cannot be produced at all. But there are some other peculiarities which deserve notice. Thus, while with every coil used and with varying batterypower it was found that magnesia alba gave 80 lines to the inch, when the machine was used the number varied in different parts of the figure from 56 to 64 . There was no partienlar mode of variation, that is, no crowding together at a special place, \&c. This irregularity in the numbers is not, however, 
a general thing; for in other cases tried, the numbers did not vary among themselves and agreed with those obtained with the coils.

The common centre of the circles, instead of being, as with the coil, halfway between the terminals, seemed to be a little nearer the positive electrode than the negative. Other experiments are, however, necessary before this can be regarded as established.

In experimenting with this machine it is necessary to avoid placing the plate too near the terminals, otherwise the powder becomes electrified, and the plate also, and the resulting figures are combinations of those showing the distribution of the electricity upon the plate, and the undulatory effect discussed in this paper.

Most of the figures obtained with the machine were caused by the spark passing between knobs. They are imperfect at the sides, in consequence of the undulatory effect being prevented from making itself felt in those directions by the solid body of the knob coming between. Thus the portion of the circles shown are at right angles to the direction of the spark. The figure can of course be obtained from sparks taken between points, but it is more difficult. It was particularly noticed in the course of these and some other experiments that, whilst substituting a knob for a point in a Wimshurst or other machine increased the length of spark obtainable, it was just the opposite with a coil ; for here the spark is considerably reduced if taken between two knobs. The longest spark with a coil is obtained either between two points; or between one point and one knob or plate.

It was also noticed that under the positive electrode the powder was scattered so as to cause a space. This is sometimes, but not always, the case under the negative.

11. Production of the Cleared Space.-It will be observed that the more or less elliptical space in the middle of the figures is not present in all. It is only produced when the plate is held close up to the terminals and when the vigour of the spark is considerable. At a first glance at a figure containing the clear space, it appears that the lines are crowded together at the ends of the major axis of the ellipse. Closer examination and careful measurement will show, however, that this is not the case, for the number of lines per unit of length is the same whether measured at the ends of the major or of the minor axis. In fact the appearance is just that of concentric circles, formed of the powder, with the material composing the smaller circles swept up so as to form the irregular ellipse. 
From this fact, and also that the circles can be produced without any clearing of the powder, I am led to conclude that the production of the circles is due to an entirely different cause to that producing the space, but that both are necessary accompaniments of the disruptive discharge.

12. Discussion of Results. - When these figures were first obtained it was imagined that they were due to the sound which accompanied the spark, and in fact gave a graphical representation of the sound-waves. This view was to some extent confirmed by finding that the same substance gave the same number of waves in the same space. If this be so, however, then there ought to be no difference in the numbers obtained with different powders; for the sound of the spark produced by a coil is remarkably constant, and, if such a term can be rightly applied to it, it is of unvarying pitch. This view, however, is also disproved by the measurements ; for if it be taken that the lines show the phases of the undulatory movement, then the longest distance between similar phases is that given by powdered chalk, viz. $\frac{1}{40}$ of an inch. But the upper limit of vibration producing a sound-wave may be taken as equal to 40,000 per second, giving a length for the wave of as nearly as possible one third of an inch, a distance thirteen times greater than the longest given by these experiments. It is therefore evident that the vibrations producing these curves and those producing the sound of the spark are not identical.

From the fact that the number given by a mixture is intermediate between those of its constituents, we should be led to conclude, since the density of a mixture follows the same law, that therefore this is the factor which regulates the number given by any particular substance. If this be the case, then the powders should arrange themselves in a series, with those of the highest density at the top and thuse of the lowest at the bottom. A glance at the tables of results will, however, show that no such order is observed. Thus we have silica giving a higher number (88) than the heavy oxides of lead (64); magnesia alba, a substance of very low specific gravity, appearing high up in the list; and tannin, also of low specific gravity, on the other hand, appearing low down. What conditions, if any, regulate the number of these lines I have hitherto been unable to determine. Before any generalization. can be made it is necessary to examine a very much larger number of substances, and experiments are being conducted with this purpose. At present, indeed, I am not disposed to attach much importance to the absolute length of any one of these undulations, but rather to the great similarity of the 
measurements as a whole. For although it is likely that errors may occur in some of the individual members, it is hardly possible that the whole are erroneous. It will therefore follow that undulations of a length of about one sixty-fourth of an inch (taking the mean measurement) accompany the disruptive discharge.

The photographs from which the figures in the Plate are copied were taken for me by Mr. Dunscombe, of Bristol, and were printed from the negatives without the latter being touched in any way.

Note, June 9, 1888.-Since the above was written, I have been informed by Prof. Rücker that he has an apparatus in his possession, made by the late Dr. Guthrie, which gives somewhat similar results. This was copied from one exhibited at the Loan Exhibition of Scientific Apparatus in 1879 . It consists of an elliptical dish with vertical walls. Sand is scattered over the bottom, a glass plate placed over the top, and a series of electric sparks produced at one focus of the ellipse. The sand will then be found to arrange itself in a series of circular curves around the other focus. The curves thus produced bear a striking resemblance to those exhibited in the Plate accompanying this paper, and are of course due to the same cause.

XXXII. On the Recalculation of certain Specific Heats at High Temperatures, and the Specific Heat of Water. By William Sutherland, M.A., B.Sc.*

I $N$ the course of some work on molecular physics I was led 1 to search for some accurate measurements of the specific heats of liquids at high temperatures, and found that, although Hirn had conducted some good experiments, his results had not been accepted on account of their disagreement with those of Regnault. Thus, while for the heat necessary to raise ether from $0^{\circ}$ to $t$ Hirn gives the formula

Regnault gives

$$
q=\cdot 564 t+\cdot 000799 t^{2}-\cdot 0_{5} 268 t^{3}+\cdot 0_{7} 181 t^{4}
$$

For alcohol Hirn gives

$$
q=\cdot 529 t+\cdot 000296 t^{2}
$$

$$
q=\cdot 4229 t+\cdot 00274 t^{2}-\cdot 0_{4} 132 t^{3}+\cdot 0_{7} 506 t^{4}
$$

while Regnault's formula is

$$
q=\cdot 5475 t+\cdot 00112 t^{2}+\cdot 0_{5} 221 t^{3}
$$

The great differences between the values for the specific heats

$$
\text { * Communicated by the Author. }
$$



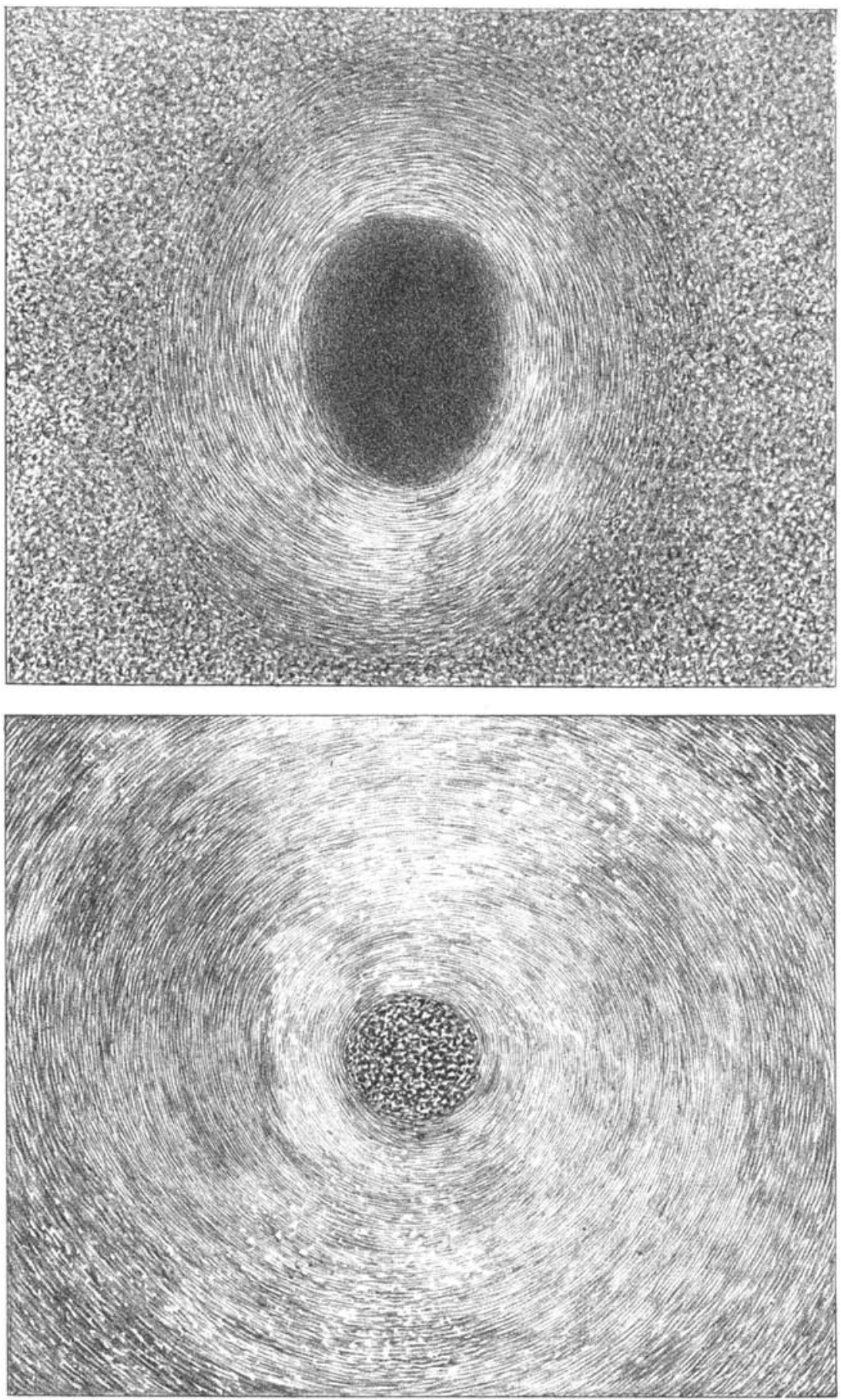